\title{
Suggestions for the Workshop
}

\section{Ingenious Expedients of Resourceful Mechanics}

\section{Handy Man's Medicine Chest}

To the Editor of the Workshop Department:

In looking over Handy Man's Medicine Chest, in the issue of September 9th, I notice that the collodion dressing with aristol or iodoform added calls for 50 grams to the ounce. I intended this to read 50 grains. This amount would do more harm, but as there are only 31.1 grammes to the ounce, by using 50 grammes of aristol you have more aristol than collodion, which I fear would be an almost useless mixture. The mistake of realing grams for grains is often made by druggists, and for this reason I believe that when grammes is intended, it should be written out in full (grammes).

$$
\text { William R. Inghram, M.D. }
$$

\section{Dangers of Gasoline Vapor Cleaning} To the Ed:tor of the Workshop Department:

The description of an automobile cleaning device published among the "Suggestions for the Workshop." on page 276 of September 23d issue, is of considerable interest from an insurance point of view, from the fact that the vapor from one pint of gasoline will make 200 cubic feet of air explosive. The device seems to be an excellent gas generator; a flame sonie distance away will ignite the vapor, and the operator of the cleaner will never know what hit him.

Would it not be well to caution your readers against the use of such a dangerous machine?

P. D. C. Steivard.

\section{Holder for Filing Small Screws}

\section{By B. F. D.}

W HEN a small screw is to be filed down to shorten $V_{\text {it, it is not advisable to put it in a vise for fear }}$ of damaging the threads.

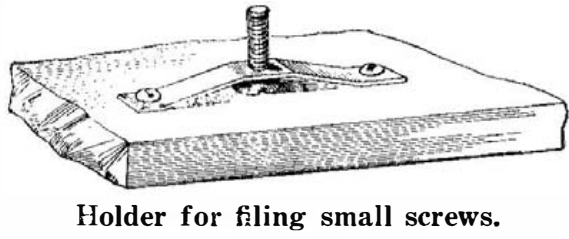

A small piece of soft iron may be bent and drilled in the manner $\mathrm{s}^{1}$ own in the illustration, and then screwed or nailed to the bench top with the screw in the position shown.

\section{Refacing Valve Seats}

By Albert F. Bishop

WEN refacing the valve seats of an automobile $W$ eng:ne, it is usually the practice to make a reamer out of cast steel and temper and grind it to si:e. This is rather a tedious task and somewhat expensive. Recently a friend of the writer found it necessary to reface the valve seats of his four-cylinder automob:le engine, which meant that there were eight valves to be treaterl. Instead of adopting the usual method, the writer suggested that he make his reamer of soft steel, and fit it with cutting edges by sawing through the beveled edge of the reamer with a hack saw in four places and driving in four pieces of clock spring. These cutters were filed down nearly

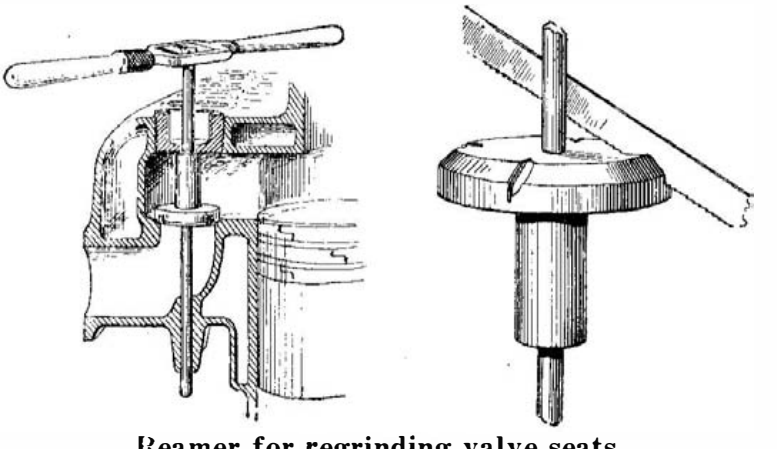

to the surface of the reamer. The bevel was finished in the lathe with the grinder, allowing the clock spring strips to project about 0.02 of an inch, or less, from the surfe.ce. Small grooves were filed in the reamer in front of the cutting edges to allow for clearance of chips. The lower end of the reamer was made to fit nicely in the guide for the valve seat. One of the plugs in the engine directly over the valve was bored out to fit the upper part of the reamer. This plug not only held the reamer accurately, but also acted as a feed; for it could be screwed down as the reamer was revolved. The eight seats were reface with perfect ease, the last one cutting as well as the others. When the work was completed, the hole. bored in the plus was stopped up with a piece of metal, and the plug was replaced in the engine for service. The valves were placed in the lathe and faced off enough to true them, after which they were inserted in the engine and ground to a fit with powdered glass and oil.

\section{Laying Out Work for Drilling}

\section{By George F. Brown}

$A$ QUICK and accurate way of obtaining an impres $\mathbf{A}_{\text {sion of the holes already drilled in a flange when a }}$ new flange or cap is to be fitted to it, is to rub a piece of chalk down into the hole so that the edge will scrape off a small amount, forming a bead of chalk that is slightly raised above the surface of the flange. On the flange thus prepared the new flange is laid in
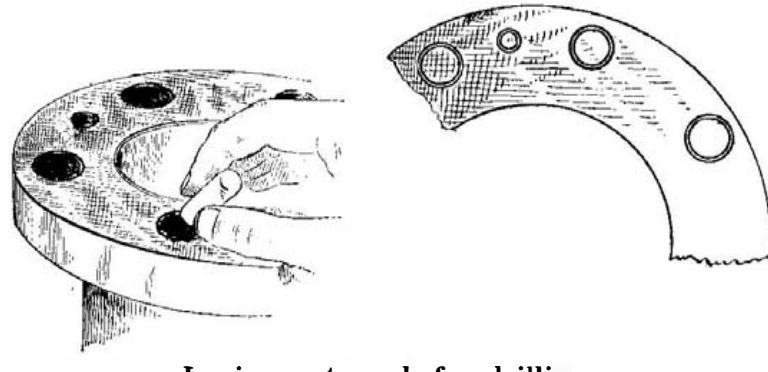

Laying out work for drilling.

the exact position in which it is to be bolted. On removing the chalked flange an accurate tracing of each hole will be found on the new flange. These circular tracings can be centered and drilled and they will be sure to mate the holes in the other flange when it is replaced for jolting.

\section{Magnetic T-Square}

By William Grötzinge W HEN much hatching is to be done there is al position because it is necessary to hold the T-square and at the same time to manipulate the triangle and the ruling pen. To eliminate this trouble the writer took two small electro-magnets out of an old doo bell, and fastened one on each end of the head of the

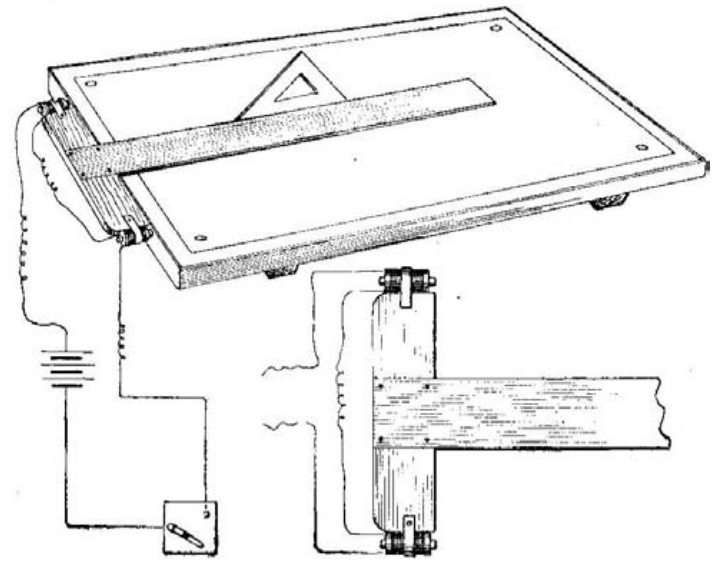

Holding a T-square in place with electro-magnets.

T-square, taking care to get the magnet cores on a line with the edge of the head.

Then a piece of thin iron band was fastened to the edge of the drawing board with several small screws. The magnets were connected in series with a battery and switch. When turning on the current, the mag. nets will hold the T-square firmly against the drawing board. Then all one needs to do is to attend to the triangle and the pen. This will eliminate slipping of the T-square and make for accurate work.

\section{Flywheel Brake \\ By C. M. Moon}

THE brake illustratel herewith was designed for I use on the flywheel of a heavy Gordon job printing press, having the driving motor belted to the flywheel. It was necessary to construct the brake in such a way that the parts would not interfere with the driving belt.

As will be seen by referring to the illustration, $M$ represents the motor; $A$ is the brake shoe, which is supported by two legs, $B$, with the belt passing between them. These legs are bolted to the block which is securely fastened to the floor. The coil springs $C$ assist in holding the brake shoe away from the wheel, and also keep the ends of the shoe from rubbing. The bralie shoe is connected by means of two drawbars $D$, one on either side, with the two bell ranks $\boldsymbol{G}$ which are screwed to the sides of the foot lever $K$. These bell cranks, drawbars, and brake shoe legs are made from $3 / 4$-inch band iron, $1 / 4$ inch thick. The foot lever is connected with the block $H$ by means of a 6 -inch strap-hinge $I$, as will be noted in Fig. 2 of the sketch, and the block $H$ is securely fastened to the floor with lag screws. The coil spring $I$ holds the outer end of the foot lever about three inches above the floor, and also assists in holding the brake shoe away from the flywheel, except when stopping the machine. The spring used was an old-fashioned bed spring, which answers the purpose very well.

The brake shoe, foot lever, and floor blocks should

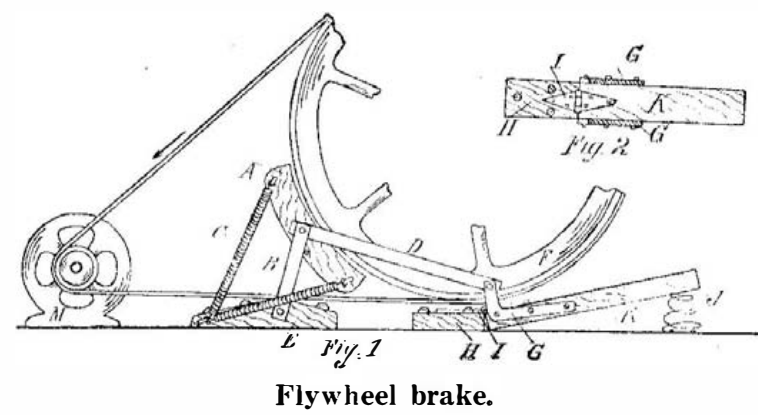

be made of hard wood if possible, but any kind will do the work. If desired, the shoe may be faced with a piece of leather belting, smooth side outward, which gives it a much better grip on the wheel.

This brake is very powerful on account of the leverage obtained at the foot lever, and also because of the fact that the brake-shoe legs are not placed perpendicularly, but incline somewhat toward the flywheel; thus when the brake "s applied, the friction tends to force the shoe more tightly under the wheel. With this device the machine may be brought to a stop slowly, or in case of accident, almost instantly, by increasing the pressure upon the foot lever.

\section{Repairs to a Cistern} By J. W. Romig

FRIEND of mine has a traction engine, and one Aay while on the road he found that he had very little water left. Just at this time they were passing an old deserted house whose cistern was about half

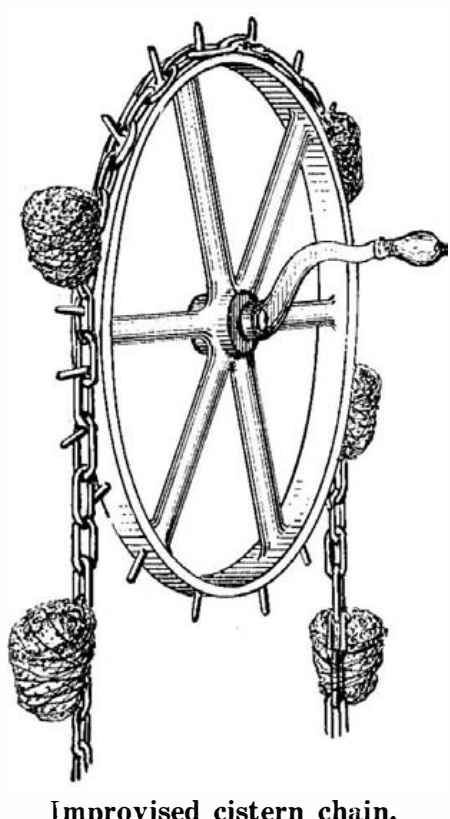

full of water, but the rubber buckets were rotted off; so taking some cotton waste from the engine he made buckets with this, and got enough water to complete his run.

\section{Workshop Notes}

To Sharpen Chisels. - Often one has chisels of awkward shape, and no stone with which to sharpen them. If a piece of wood is cut to fit the chisel, it can be used in place of a stone, by dipping it in a mixture of oil and powdered emery, and then manipulating as an ordinary stone.-B. Francis Dasinel.L.

Soldering Galvanized Iron.-Raw soldering fluid is generally used on the soldering copper when it is desired to solder galvanized iron. However. before commencing to solder, it is desirable to dip the soldering copper while hot in a solution of sal-ammoniac and water. This will retain the tin on the point of the soldering copper, which would otherwise soon disappear.-A. F. B. 